\title{
The use of keywords for delevering immediate performance feedback on teacher competence development
}

\section{Citation for published version (APA):}

Coninx, N. S., Kreijns, C. J., \& Jochems, W. M. G. (2013). The use of keywords for delevering immediate performance feedback on teacher competence development. European Journal of Teacher Education, 36(2), 164-182. https://doi.org/10.1080/02619768.2012.717613

DOI:

10.1080/02619768.2012.717613

Document status and date:

Published: 01/01/2013

\section{Document Version:}

Publisher's PDF, also known as Version of Record (includes final page, issue and volume numbers)

\section{Please check the document version of this publication:}

- A submitted manuscript is the version of the article upon submission and before peer-review. There can be important differences between the submitted version and the official published version of record. People interested in the research are advised to contact the author for the final version of the publication, or visit the $\mathrm{DOI}$ to the publisher's website.

- The final author version and the galley proof are versions of the publication after peer review.

- The final published version features the final layout of the paper including the volume, issue and page numbers.

Link to publication

\section{General rights}

Copyright and moral rights for the publications made accessible in the public portal are retained by the authors and/or other copyright owners and it is a condition of accessing publications that users recognise and abide by the legal requirements associated with these rights.

- Users may download and print one copy of any publication from the public portal for the purpose of private study or research.

- You may not further distribute the material or use it for any profit-making activity or commercial gain

- You may freely distribute the URL identifying the publication in the public portal.

If the publication is distributed under the terms of Article 25fa of the Dutch Copyright Act, indicated by the "Taverne" license above, please follow below link for the End User Agreement:

www.tue.nl/taverne

Take down policy

If you believe that this document breaches copyright please contact us at:

openaccess@tue.nl

providing details and we will investigate your claim. 
This article was downloaded by: [Eindhoven Technical University]

On: 10 February 2014, At: 01:03

Publisher: Routledge

Informa Ltd Registered in England and Wales Registered Number: 1072954 Registered

office: Mortimer House, 37-41 Mortimer Street, London W1T 3J H, UK

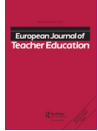

\title{
European J ournal of Teacher Education
}

Publication details, including instructions for authors and subscription information:

http:// www.tandfonline.com/loi/ cete20

\section{The use of keywords for delivering immediate performance feedback on teacher competence development}

\author{
Nele Coninx ${ }^{a}$, Karel Kreijns ${ }^{b} \&$ Wim J ochems ${ }^{a}$ \\ ${ }^{a}$ Eindhoven School of Education, Eindhoven University of \\ Technology, Eindhoven, the Netherlands, \\ ${ }^{b}$ Teacher Education Institute, Fontys University of Applied \\ Sciences, Sittard, the Netherlands, \\ Published online: 24 Sep 2012.
}

To cite this article: Nele Coninx, Karel Kreijns \& Wim J ochems (2013) The use of keywords for delivering immediate performance feedback on teacher competence development, European J ournal of Teacher Education, 36:2, 164-182, DOI: 10.1080/ 02619768.2012.717613

To link to this article: http:// dx.doi.org/ 10.1080/ 02619768.2012.717613

\section{PLEASE SCROLL DOWN FOR ARTICLE}

Taylor \& Francis makes every effort to ensure the accuracy of all the information (the "Content") contained in the publications on our platform. However, Taylor \& Francis, our agents, and our licensors make no representations or warranties whatsoever as to the accuracy, completeness, or suitability for any purpose of the Content. Any opinions and views expressed in this publication are the opinions and views of the authors, and are not the views of or endorsed by Taylor \& Francis. The accuracy of the Content should not be relied upon and should be independently verified with primary sources of information. Taylor and Francis shall not be liable for any losses, actions, claims, proceedings, demands, costs, expenses, damages, and other liabilities whatsoever or howsoever caused arising directly or indirectly in connection with, in relation to or arising out of the use of the Content.

This article may be used for research, teaching, and private study purposes. Any substantial or systematic reproduction, redistribution, reselling, loan, sub-licensing, systematic supply, or distribution in any form to anyone is expressly forbidden. Terms \& Conditions of access and use can be found at http://www.tandfonline.com/page/termsand-conditions 


\title{
The use of keywords for delivering immediate performance feedback on teacher competence development
}

\author{
Nele Coninx ${ }^{a *}$, Karel Kreijns ${ }^{b}$ and Wim Jochems ${ }^{a}$ \\ ${ }^{a}$ Eindhoven School of Education, Eindhoven University of Technology, Eindhoven, the \\ Netherlands; ${ }^{b}$ Teacher Education Institute, Fontys University of Applied Sciences, Sittard, \\ the Netherlands
}

\begin{abstract}
Literature shows that feedback that is specific, immediate and goal-oriented is effective on (pre-service) teachers' performance. Synchronous coaching gives this kind of feedback. Due to immediateness of feedback, pre-service teachers can suffer from cognitive load. We propose a set of standardised keywords through which this performance feedback can be delivered - each keyword acts as a summary for the feedback message. The construction and the selection of the keywords is aimed at the reduction of message ambiguity, while at the same time a low level of cognitive load on the pre-service teacher must be maintained. An in vivo pilot-study with 40 respondents (pre-service teachers and their coaches) supported our hypothesis that usage of such sets of standardised keywords will mitigate the levels of ambiguity and cognitive load. These findings and other considerations for additional research using immediate performance are addressed.
\end{abstract}

Keywords: performance feedback; BIE device; pre-service teachers; cognitive load; ambiguity

\section{Introduction}

Many countries today are facing the issue of teacher shortages due to the demographic aging and drop-out of teachers early in their career (e.g. in the Netherlands: Commissie Leraren 2007). Teacher preparation and induction has, therefore, gained increased attention as a means of assisting teachers' successful entry into the teaching profession (Giebelhaus and Bowman 2002) and to reduce dropout. Studies have shown that successful entry into the profession reduces feelings of anxiety, isolation and powerlessness (Brown 2005). However, pre-service teachers reported a lack of effective support during their teacher preparation (Rushton 2003). Consequently, effective teacher preparation of pre-service teachers has become a growing concern for teacher educators, preferably in the workplace, due to the increased emphasis placed on this. Rose and Church (1998) recommended practice with performance feedback as a necessary component of any training programme that is implemented to change teacher behaviour in the classroom. There is emerging evidence supporting the effectiveness of performance feedback (Codding et al. 2005; Noell et al. 2002) Therefore, an important teacher-preparation technique is performance feedback.

*Corresponding author. Email: ns.coninx@fontys.nl 
In this article we first elaborate on performance feedback: pre-service teachers should receive immediate (Scheeler and Lee 2002), specific (Shute 2008) and goal oriented feedback (Hattie and Timperley 2007) on their performance within classrooms. We then introduce synchronous coaching as a method for delivering specific immediate feedback during class performance. In synchronous coaching we use a Bug In Ear (BIE) device, which is actually an ear piece. However, synchronous coaching is not without problems. We make clear that ad hoc whispering words or even whole sentences may introduce (1) interpretation problems regarding the content of the feedback message due to ambiguity and (2) cognitive load as a result that pre-service teachers have to divide their attention between the class and the interpretation of the feedback. Longer messages will therefore contribute to more cognitive (over)load. The solution is that we constructed a pre-defined set of keywords for decreasing the levels of ambiguity and cognitive load. We hypothesise that the use of a set of keywords will mitigate these problems as each keyword will act as a shortcut for the feedback message. The construction and selection of the keywords is our next topic. The keywords were constructed to provide specific feedback on the three main problems (Houtveen, Versloot and Groenen 2006) preservice teachers face (achieving effective classroom management, activating pupils towards their learning process and catering for the individual needs of pupils). In order to test the hypothesis we executed an in vivo pilot-test in which two different modes were compared: (1) the traditional ( $a d$ hoc) way of whispering words or sentences (control group) and (2) the use of a set of keywords (experimental group).

\section{Performance feedback}

Performance feedback is a systematic way of providing guidance to pre-service teachers while they acquire new skills (Noell et al. 2000; Sutherland, Alder, and Gunter 2003). Performance feedback helps learners determine performance expectations, judge their level of understanding and become aware of misconceptions. It also provides messages about the best approaches for correcting mistakes and improving performance (Kulhavy and Stock 1989; Mory 1992). To increase the effectiveness of performance feedback, the feedback should be (1) specific (Shute 2008), (2) goal oriented (Hattie and Timperley 2007) and (3) immediate (Scheeler and Lee 2002).

Feedback is specific when it provides information about particular responses or behaviours (Shute 2008). The feedback should be directed at the task (Black and Wiliam 1998) and detailed (Ross and Tronson 2005). Research findings demonstrate that when the pre-service teacher's feedback is focused, specific, clear and obtainable, learning to teach is more effective (Peard and Hudson 2006). Research findings also demonstrate that specific feedback results in positive changes in teacher behaviour (Scheeler, Ruhl, and McAfee 2004). According to Locke and Latham (1984), specific feedback is more effective than general feedback, primarily because it focuses on the pre-service teachers' attention, resulting in the feedback being more directed. Specific feedback could also be made more manageable by narrowing the range of possible interpretations of the feedback, thus reducing misunderstanding (Sweller 1990). Possible meanings of a feedback message could cause ambiguity, resulting in higher levels of cognitive load. Ambiguity and cognitive load could lead to lower levels of learning (Kluger and DeNisi 1996; Sweller, Van Merriënboer, and Paas 1998) or even reduced motivation to respond to the feedback (Ashford 1986). 
Goal-oriented feedback provides pre-service teachers with information about their progress towards a desired goal (or a set of goals) rather than providing feedback on discrete responses (i.e., responses to individual tasks) (Shute 2008). Feedback should provide cues and information about teaching behaviour that may lead to the development of more effective and efficient actions of pre-service teachers learning how to teach (Hattie and Timperley 2007). Research has demonstrated that learners' motivation and engagement depend on a close match between a learner's goals and their expectations that these goals can be met (Fisher and Ford 1998). Therefore, communicating quality goal-oriented feedback was a key element in enhancing learning. In this process, judgments are made about the match between evidence of achievements and standards (Knight 2002). Quality feedback that promotes learning should include (non-evaluative) descriptions or evidence of the features of a teacher's work, evaluative comments linked to criteria that indicate those features adding to or detracting from high quality and setting targets for improvement (Sadler 1989, 1998). Sadler (1989) highlighted that quality feedback can help learners to identify the learning gap between their current level of achievement and the desired (higher) level of attainment and support them to close this learning gap.

Immediate feedback is defined as feedback delivered by the coach immediately after the target behaviour occurs (Scheeler et al. 2008; Scheeler and Lee 2002). Many field studies demonstrate the value of immediate feedback (Shute 2008). Therefore, in teacher practice, feedback should be given preferably during class performance (immediate feedback) rather than after the performance (delayed feedback) to be most effective (Coulter and Grossen 1997; O'Reilly et al. 1992; Scheeler et al. 2006; Van Houten 1980). Immediate feedback has been used with pre-service teachers to effectively change faulty teaching behaviours (Rathel et al. 2008).

Immediate feedback has a number of advantages. One advantage is that when immediate feedback is given, coaches are able to give more feedback in less time (efficiency of learning) and are able to model effective instruction techniques (O'Reilly et al. 1994). If coaches used immediate, specific performance feedback with pre-service teachers, this results in more opportunities to practice, faster (more efficient) acquisition of new behaviours by teachers and more careful and efficient coaching sessions (Scheeler et al. 2006). Another advantage of using immediate feedback is that it provides learners with an opportunity to change target behaviours while practicing a skill, as opposed to their repeating errors until feedback is delivered, after the fact (Coulter and Grossen 1997).

\section{Synchronous coaching}

The underpinning pedagogical framework of synchronous coaching is a feedback mechanism (Bennett et al. 2010; Codding et al. 2005; Farrell and Chandler 2008). A coach helps a pre-service teacher to adopt evidence based actions of teaching by giving performance feedback. This feedback should include mastery criteria to ensure that the pre-service teacher can demonstrate effective teaching actions (goals).

There are different ways to give immediate performance feedback. One way is that a coach can interrupt or even stop the lesson and give specific performance feedback. This method has obvious disadvantages such as a decrease of concentration and potentially a reduction of the self-esteem of the pre-service teacher. 
Furthermore, because of the disruption, there is valuable lesson time lost (Scheeler et al. 2006).

A more preferred method is synchronous coaching. Synchronous coaching provides pre-service teachers with immediate, on-the-spot feedback while these preservice teachers are engaging in classroom instruction (Giebelhaus 1994). Although researchers have used various forms of technology to provide immediate feedback, the Bug In Ear (BIE) is the most widely-used device. Researchers had variously referred to this technology as a 'Whisper-in-my-ear (WIME)', 'wireless earphone', a 'mechanical third ear device' or an 'electronic audio-cueing system' (Rock et al. 2009). Most of us know BIE technology as the tiny earpieces that people wear while they talk on their cell phones instead of having to hold the phone to their ear. Bug-In-Ear technology is referred to a small ear bud receiver that transmits verbal communication from a transmitter to a receiver. In general, BIE technology has been used effectively in a number of disciplines to improve practices in the field (Franklin et al. 2007). Bug-In-Ear technology has evolved from its initial use in psychotherapy (Korner and Brown 1952) to many other professions including dentistry, special education, counselling, security, sports and the general public (Goodman 2005; Scheeler and Lee 2002). Despite the knowledge base of synchronous coaching, it is not yet commonly used in the field of secondary education (Scheeler et al. 2006).

When using BIE technology in a teacher preparation situation, the coach delivers prompts and feedback to the pre-service teacher wearing the ear piece to provide messages or cues for behaviour. Synchronous coaching using BIE technology provides immediate performance feedback during instruction that doesn't interfered with teaching, except to cue the pre-service teacher to use effective teaching behaviour (Goodman et al. 2008). The pre-service teacher is the only one to hear the prompts and can then decide what to say or do next (Goodman and Duffy 2007). Research on this delivery of feedback that is not disruptive to the learning process of pre-service teachers is, therefore, urgent (Scheeler, Ruhl, and McAfee 2004).

\section{Reflections on synchronous coaching}

Literature on synchronous coaching reports very promising findings. Pre-service teachers overwhelmingly give the technology favourable reviews and state that they can easily attend simultaneously to two sets of verbal stimuli (i.e., classroom students and a university supervisor) (Rock et al. 2009). Using this type of coaching allows coaches to give more cues on new behaviours to pre-service teachers in less time, promoting efficiency of learning. In addition, such efficiency is likely to reduce frustration on the part of pre-service teacher who is attempting to acquire new behaviours but who otherwise must wait for feedback on their performance (Scheeler et al. 2006). Although synchronous coaching is a promising technique, it is not without problems.

Too frequent messages disrupt the pre-service teacher's train of thought (Hunt 1980). However the use of short, specific messages may be helpful in preventing disruptions in the flow of instruction (Scheeler and Lee 2002). The coach should restrict the length and frequency of his messages as a means of keeping nuisance and confusion factors to a minimum (Herold, Ramirez, and Newkirk 1971).

Goodman et al. (2008) state that besides restricting the number of messages, the messages should also be predictable and should be used only in targeted 
lessons. Moreover, inappropriate coach intervention can largely be averted if the coach and pre-service teacher agree in advance on the behavioural objectives they both wish to achieve (Herold, Ramirez, and Newkirk 1971). That way, feedback messages are more meaningful for the pre-service teacher (Chow et al. 2010) and enable the coach to cue on performance outside the target area (Giebelhaus and Cruz 1994).

Coaches should not delay feedback messages for fear of unsubstantiated adverse instructional momentum effect. They should, however, investigate ways to provide immediate performance feedback in the least intrusive manner (Scheeler et al. 2006).

So, the feedback message has to be short to minimise the likelihood that the BIE device would be distracting (Scheeler, Macluckie, and Albright 2008). This is because at the moment of the actual communication, two information sources compete for the attention of the pre-service teacher: the first being the actual classroom (visual and auditory information) and the second being the coach (using a BIE device - auditory information), thus, longer messages mean staying in this state for longer. In Cognitive Load Theory (Sweller 1990; Sweller, Van Merriënboer, and Paas 1998), the division of attention could produce cognitive (over)load (Chandler and Sweller 1992). Cognitive load is defined as 'cognitive capacity that is actually allocated to accommodate the demands imposed by the task' (Paas et al. 2003, 64). In our study we wanted to construct keywords (i.e., short messages) that minimise cognitive load by reducing the number of words in the message.

On the other hand, the message should also be clear. In various media theories, such as the Media Richness Theory (Daft and Lengel 1986), a clear message means that the message should not display any ambiguity. The concept of ambiguity has a variety of different connotations, ranging from ambiguity in the sense of a doubleinterpretation in linguistics, to ambiguity in the context of lack of clarity (vagueness) and to ambiguity in situations where multiple - seemingly contradictory - states or conditions could co-exist (Simpson and Weiner 1999). Research literature has noted that ambiguity has been found to influence performance levels (DeRoma, Kanetra, and Kesler 2003; Owen and Sweeney 2002). Ambiguity is not easy to resolve but more information could alleviate it. However, this could result in just those lengthy messages that we want to avoid.

For effective synchronous coaching it is therefore crucial to find the optimum between a message as short as possible, without it suffering from ambiguity, and therefore reducing the level of cognitive load of the pre-service teacher.

\section{Keywords for synchronous coaching}

In a meta-analysis of 83 studies of the reported problems of beginning teachers, Veenman (1984) found that pre-service teachers have similar problems. From a list of problems, the three main problems almost every beginning teacher reported were: (1) achieving effective classroom management, (2) activating pupils towards their learning process and (3) catering for the individual needs of pupils. Recent literature has confirmed these findings (Houtveen, Versloot and Groenen 2006; Stroot et al. 1998).

We searched in the literature for effective teaching actions for dealing with each of the three problems. Effective teaching actions are evidence-based teaching behaviours that help solve a problem. Effective teaching actions are found in the work of 
Marzano, Pickering and Pollock (2001, 2009). For example, for the problem of classroom management, we found in the literature that 'eye contact' (Marzano, Pickering, and Pollock 2001) is an effective teaching action. A pre-service teacher is measured according to these effective teaching actions. These actions serve as goals for the performance of a pre-service teacher. If a pre-service teacher feels that he/she does not use enough eye contact, he/she can get immediate feedback in an actual classroom with synchronous coaching.

This rationale is based on the following argument: that the responsibility of coaches is to specify more clearly what good teachers do and to give immediate performance feedback that increases those actions (Scheeler, Ruhl, and McAfee 2004). Thomson (1978) does not suggest that teaching style is unimportant but, rather, that teaching approaches have been overbalanced towards style without sufficient attention to the measurability of style.

So, each effective teaching action is defined in concrete (observable) classroom behaviour that a teacher should undertake to increase student achievement. Verbalising such concrete classroom behaviour could be used as a feedback message on pre-service teachers' performance and serve as a performance goal. Moreover, these feedback messages (which act as a summary for a certain effective classroom actions) have to be specific because a pre-service teacher has to know what a coach means by the message that was given on-the-spot. These feedback messages must be observable because a coach can only give immediate feedback on what he sees in the classroom. Also, the feedback messages should be as short as possible in order to reduce cognitive load, but without being ambiguous. These short, specific, goal-oriented performance feedback messages are called 'keywords'. A total of 58 keywords were selected (see Table 1. 'Feedback Dutch') for the exact messages that were given to the pre-service teachers.

\section{Methods}

The aim of this pilot study was to examine if the levels of cognitive load and ambiguity are higher in the control group (ad hoc feedback) than in the experimental group (structured feedback). Although both the control group and the experimental group were organised in the same way and followed the same protocol, they nevertheless differed in one independent variable: the use of the keywords. Coaches in the control group could make up their own messages in advance on performance development regarding the three problems of pre-service teachers (classroom management, activating instruction and catering for the individual needs of pupils) whereas the coaches in the experimental group used only the constructed, abovementioned, 58 keywords (Table 1). The control and the experimental groups followed the same protocol (based on Farrell and Chandler 2008), with a difference in Steps 2 and 3. The protocol consists of five steps:

(1) Acquaint the pre-service teacher with wearing the BIE device. This is done in a lesson where no messages should be given.

(2) Determine the competence to be developed and select appropriate keywords. Discuss the created keyword system (or create their own) to identify problems and solutions. For the experimental group, choose keywords from the constructed list (58 keywords of Table 1). For the control group, coaches 


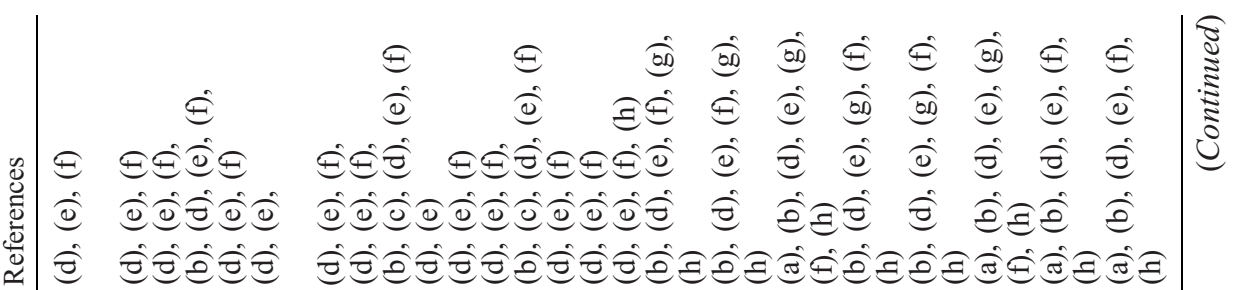

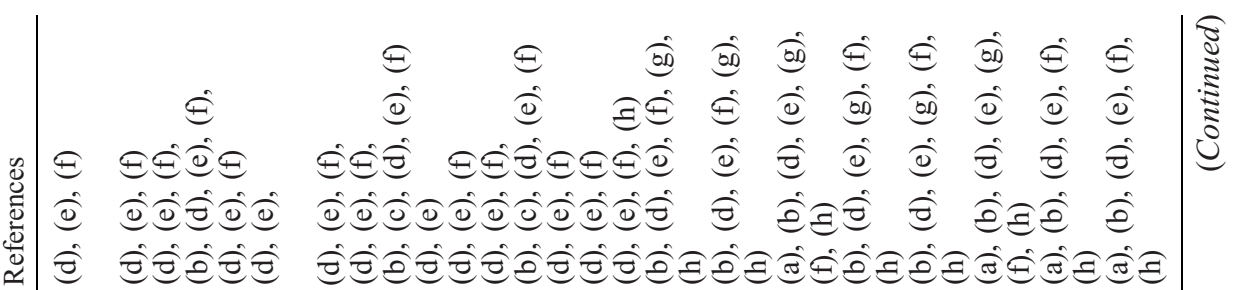

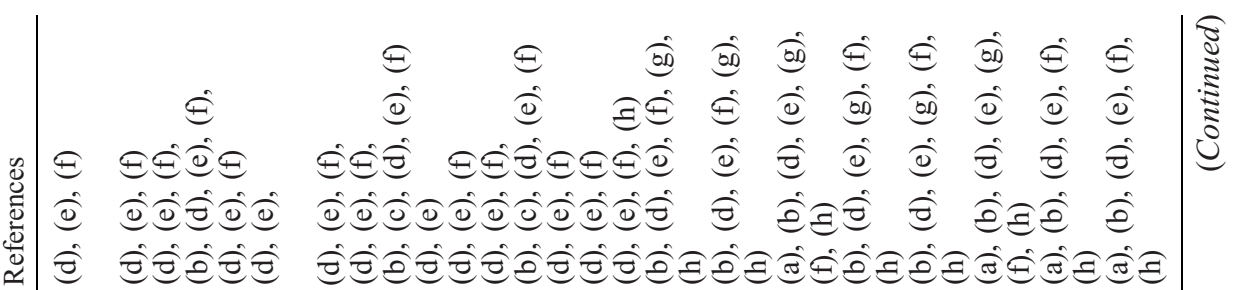

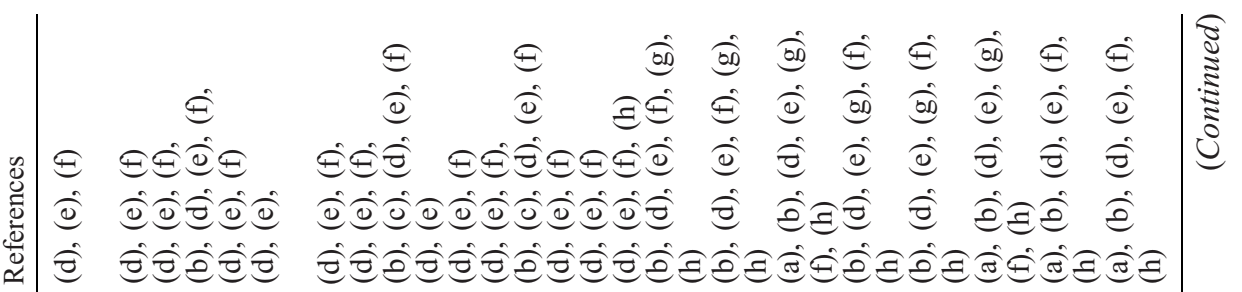

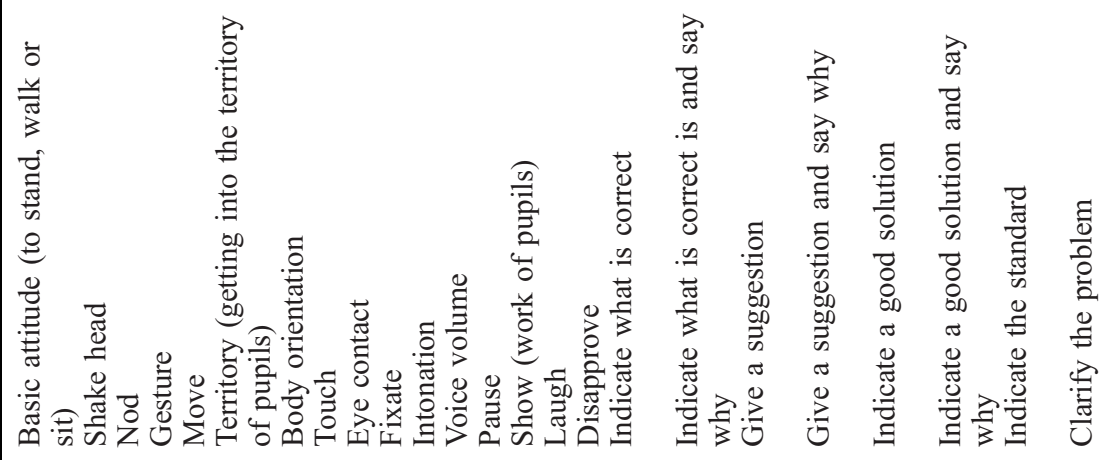

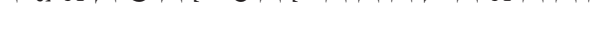

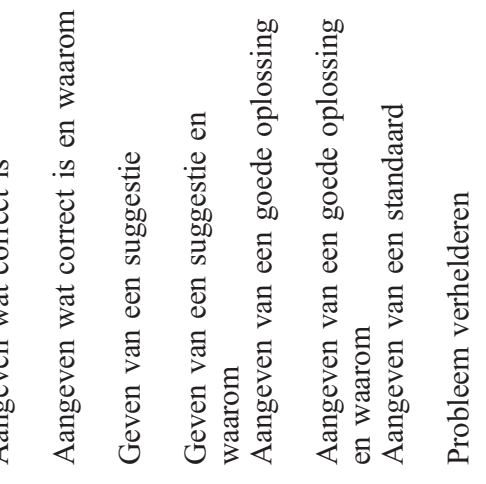

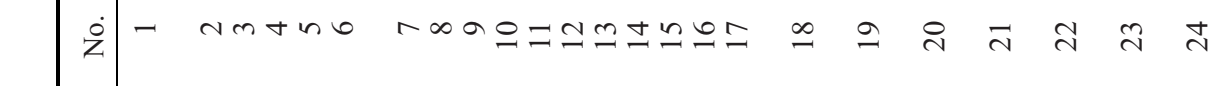

$\frac{\overline{0}}{0}$

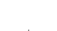

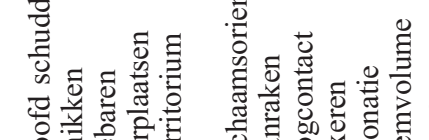

(1)

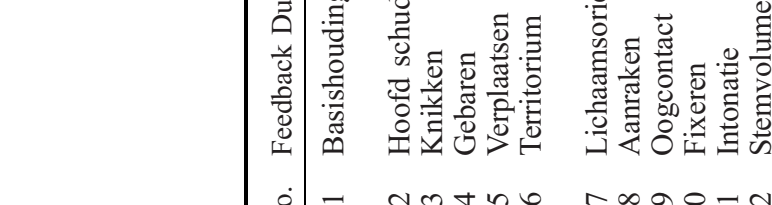




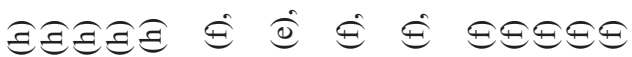

क्री $\overparen{0}$

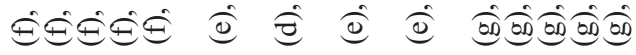

$\dot{\oplus} \dot{\theta}$

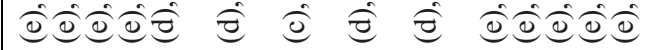

(थ)

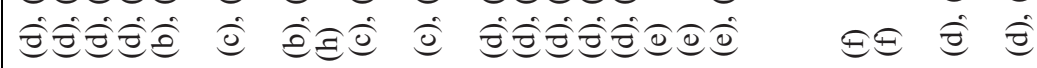

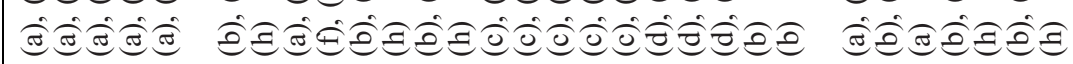

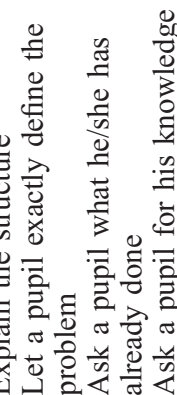

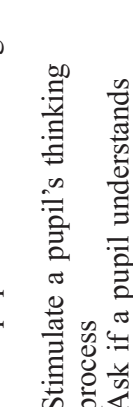

함

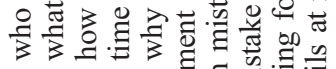

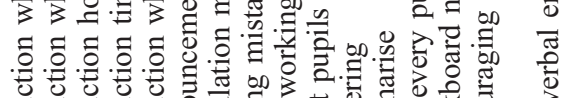

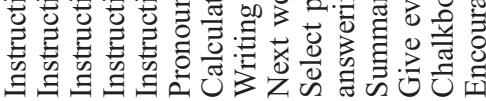

竞:
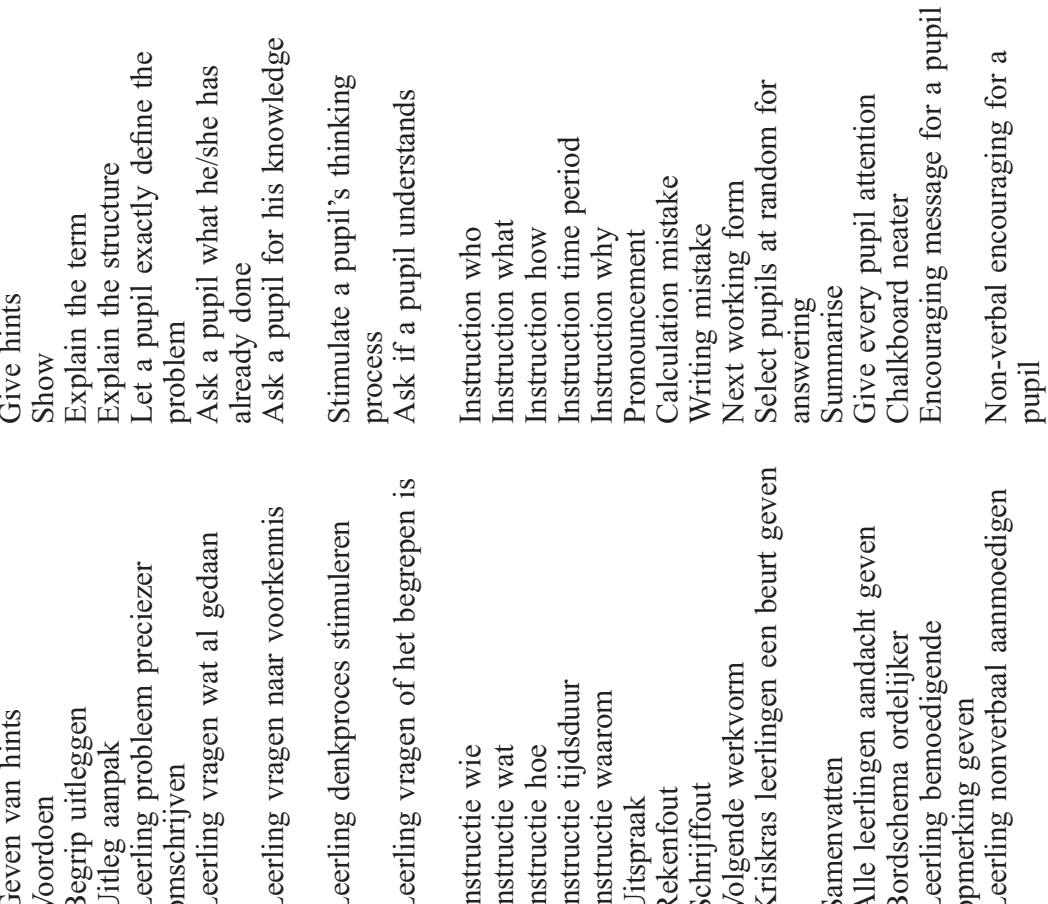
ב 言.

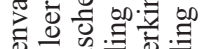

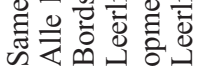

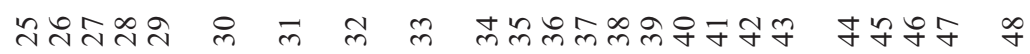

总

苞

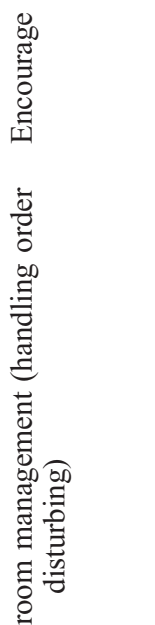




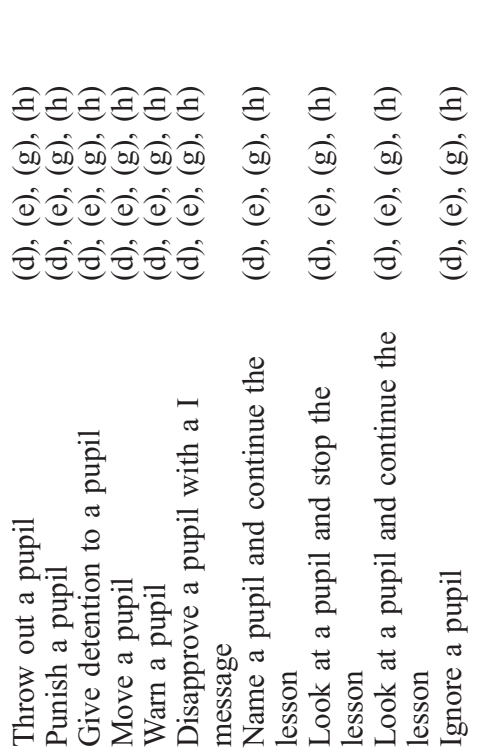

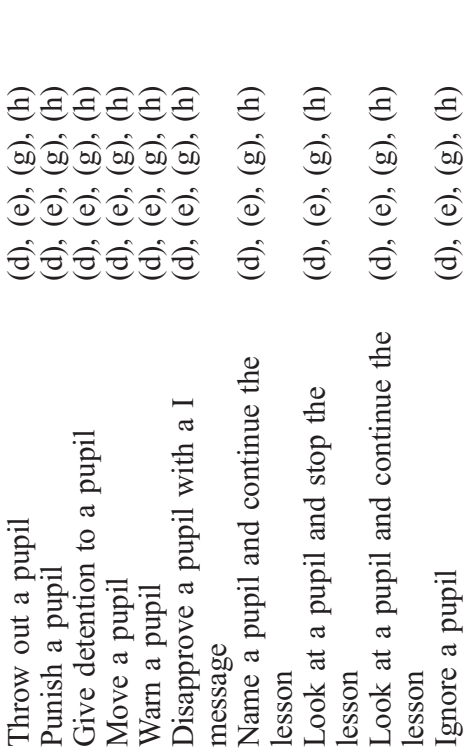

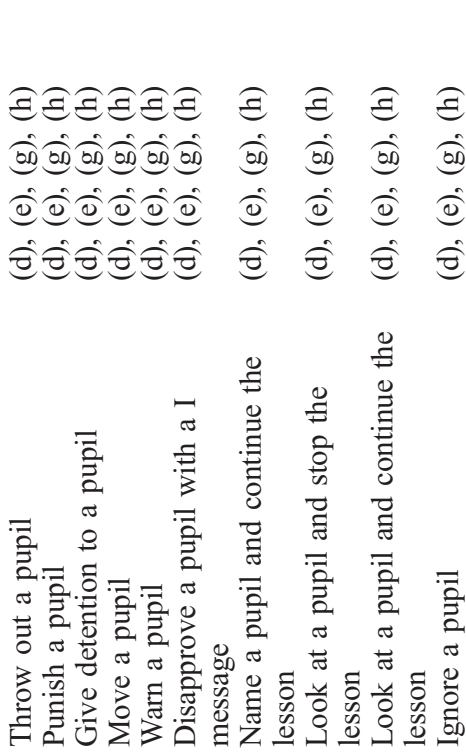

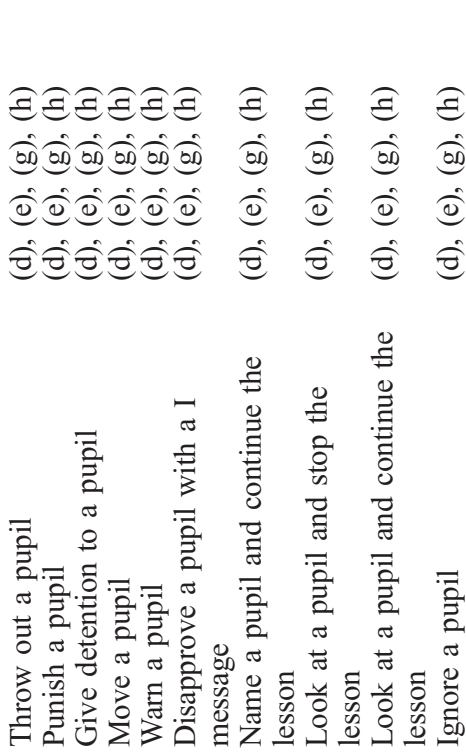

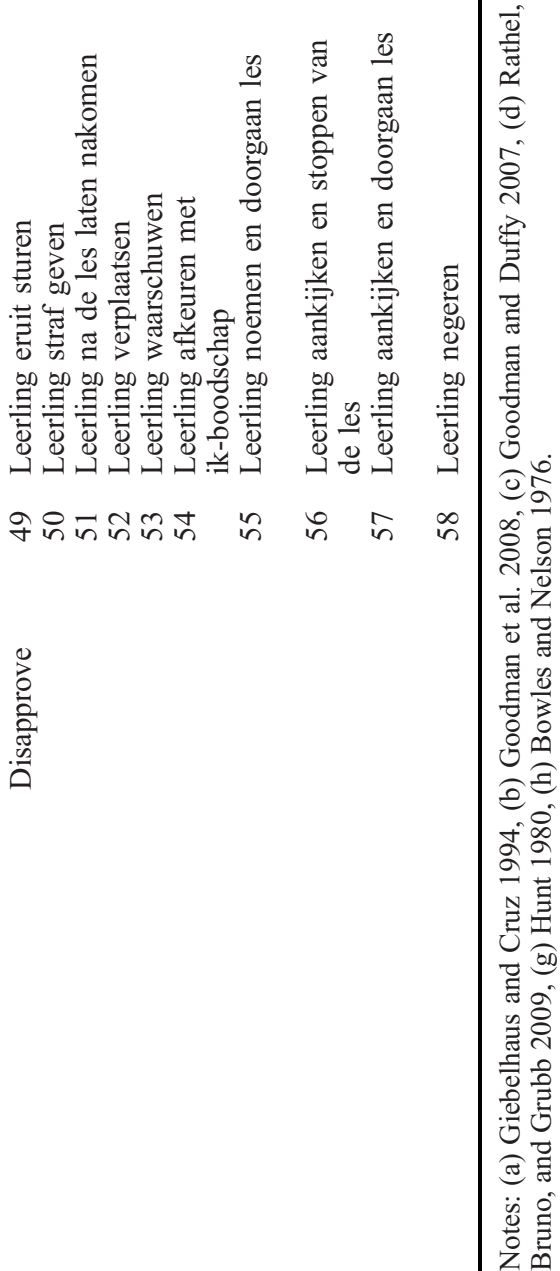


make your own keywords/sentence regarding the three problems of pre-service teachers.

(3) In the same lesson a week later, give immediate specific performance feedback (selected keywords) by using the BIE device with standard keywords in the experimental condition and using the coach's own keywords in the control condition.

(4) After the lesson, conduct a semi-structured interview per pair (coach and pre-service teacher).

(5) Fill in the questionnaire and send it back to the researcher.

This pilot study was carried out in the real-life setting of a classroom with pupils. The implementation of the synchronous coaching mode was realised through the use of a BIE device. This device was a Sennheiser DW8000 wireless transmitter with earpiece. While a pre-service teacher was teaching, a coach 'whispered' onthe-spot messages to the pre-service teacher. The coach was sitting at the back of the classroom for observing the pre-service teacher. In the Netherlands, this is a common way of coaching teachers.

Immediate performance feedback was defined as feedback delivered by the coach within three seconds after the target behaviour occurred (Scheeler and Lee, 2002; Scheeler, Macluckie, and Albright 2008). This criterion was established in a separate study that looked at the latency between a student response and a teacher consequence (Scheeler and Lee 2002).

\section{Participants}

Initially, 30 pre-service teachers were recruited from a teacher training institute for lower secondary education in southern Netherlands and randomly (15 to each group) assigned to the control group or the experimental group. The pre-service teachers were asked to find a volunteering coach who would like to participate in this study. A pre-service teacher together with a volunteering coach formed a pair. During the training of the 30 pairs, we lost 10 pairs ( 4 in the experimental group and 6 in the control group) due to: unavailability of the coach (2), sickness of the pre-service teacher (1), sickness of the coach (2), no suitable classroom (1) and not functioning material (4). So, in this study 40 participants volunteered, with 9 pairs in the control group and 11 pairs in the experimental group. A total of 20 pre-service teachers (13 male, 7 female) aged $17-34$ years $(\mathrm{M}=22.4, \mathrm{SD}=4.5)$ taught different subjects, namely geography (4), history (3), Dutch (2), English (2), physics (2), chemistry (3) and mathematics (4). Their pupils were aged between 12 and 15 years. The number of pupils in a classroom varied from 11 to 31 .

All of the 20 pre-service teachers found a volunteering coach. The coaches were experienced teachers, the pre-service teachers 'took over their lessons', while the experienced teachers sat at the back. In the Netherlands, this is a common way of workplace-based learning for pre-service teachers. The researchers chose this approach because there is some kind of trust between coach and pre-service teacher (Wong, Britton, and Gasner 2004). The 20 coaches (4 male, 16 female), aged 28-54 years $(M=38.9, S D=9.0)$, worked at 1 of 11 secondary schools. These schools are situated in southern and central Netherlands. The coaches had 3-20 years of experience $(M=6.8, S D=5.8)$ in coaching pre-service teachers (Clutterbuck 2004). 


\section{Instruments}

For each dependent variable (cognitive load and ambiguity) we used three different instruments: a questionnaire (Instrument 1), a semi structured interview with coaches and pre-service teachers (Instrument 2) and the keywords logs (Instrument 3).

Logs (Instrument 3) were differently produced for the control and the experimental group. Participants in the experimental group made use of the programme CONPAS (Coaching of Newcomers Practical Assistant Software) instead of the actual whispering of keywords. It is an in-house-developed computer programme that ensures that only the 58 pre-defined keywords are used. That is, the pre-service teacher and coach determined which of the keywords were selected as the current subset for a certain competence development. At the very moment a coach observed less competent behaviour of the pre-service teacher, she or he pressed one of the keywords in the current subset on a laptop to launch the message. Each keyword was a small audio tape of a female voice that pronounced the keyword. The pronouncement of a keyword could be activated by a mouse click (on a laptop). Because the keywords were pre-defined and audio taped in advance, the coach was enabled to 'whisper' other messages than the constructed set. The software also logged the used keywords. The ad hoc mode (control group) was established by letting the coach directly whisper into the BIE device. The coach could whisper their own created messages on the three problems. We audio taped what the coach had whispered during the lesson and described these messages ad verbatim.

The semi-structured interview (Instrument 2) consisted of three topics: (1) how did the pair (pre-service teacher and coach) experience a synchronous coaching session (which benefits, which problems), (2) did they experience any problems regarding sending and receiving messages (technical glitches, message too long, too many messages, the right moment for sending) and (3) did they experience interpretation problems (message clear, message useful).

Cognitive load was measured with three different instruments using a questionnaire (Instrument 1), an interview (Instrument 2) and keywords logs (Instrument 3). For Instrument 1, we used the one-item, nine-point cognitive-load rating scale developed by Paas, Van Merriënboer and Adam (1994). For Instrument 2 we used a semi-structured interview in which the coach and pre-service teacher were asked questions such as: Were there too many messages? Were messages too long? For Instrument 3 (keywords log) we used the average number of words per given message. We counted the words and divided them by the number of messages. From the literature we know that the preferable number is three or four words per message (Scheeler, Macluckie, and Albright 2008). The rationale is that more than three or four words per message would produce cognitive overload.

Ambiguity was also measured with three different instruments, namely a questionnaire (Instrument 1), a semi-structured interview (Instrument 2) and keyword logs (Instrument 3). There was no existing questionnaire available that measures ambiguity. Therefore we developed one on the basis of the literature. Norton (1975, 608 ) found eight characteristics for ambiguity by stating that ambiguity tolerance is: 'the tendency to perceive or interpret information marked by 1 . vague, incomplete or fragmented, 2. multiple, 3. probable, 4. unstructured, 5. uncertain, 6. inconsistent or contradictory, 7. contrary, 8. unclear meanings as actual or potential sources of psychological discomfort or threat'. For each characteristic we formulated one item 
(e.g. 'The given messages are unclear' ( $1=$ 'I fully disagree' to $5=$ 'I fully agree'). For Instrument 2 we used a semi-structured interview in which coach and preservice teacher were asked questions like: Were the messages clear? Were the messages useful? For Instrument 3 (keyword log) we used the content of the messages. The structured whispering mode can only use the keywords of the current subset representing one, two or all of the three main problems. In the ad hoc whispering mode we analysed to which problem (classroom management, didactical instruction and catering for the individual needs of pupils) each message referred. If there were other problems addressed (than the three main problems), the chance that a coach and a pre-service teacher had discussed this beforehand was small because of the given protocol (only address the three main problems). The rationale was that if there were other problems addressed without being discussed on beforehand, this could produce ambiguity. Interrater agreement data were collected on 95 of the 226 messages $(42 \%)$ of all verbatim messages. The first author coded each message as meeting the selection criteria (one of the three problems) or not. A graduate research assistant provided agreement on each message using the same selection criteria. According to Bijou, Peterson and Ault (1968), inter-rater agreement is the number of agreements divided by the sum of agreements $(n=86)$ and disagreements $(n=9)$. Inter-rater agreement was .91 , which is sufficient.

For analysis of the semi-structured interviews (Instrument 2), we used the analysis of Westers and Peeters (2004). By a process of member check and peer debriefing we tried to guarantee the quality of the results. Two researchers interviewed the respondents. The data were analysed by two researchers separately. Each interview was written ad verbatim. For each interview, one researcher searched for codes (i.e. clusters of answers). Exact agreements were considered as those in which the two researchers provided the same code. For the disagreements, the agreed consensus for a code was used.

\section{Results}

We measured two dependent variables: cognitive load and ambiguity. For cognitive load we used three different instruments. For Instrument 1, an independent-samples $t$-test indicated a significant difference $(\mathrm{t}[n]=20, p=.0 .044)$ related to the cognitive load scale for the control group $(M=4.33, S D=2.12)$ and the experimental group $(M=2.45, S D=1.75)$. The magnitude of the difference in the means was large (Cohen's $d=1.03$ ). Pre-service teachers experience significantly less cognitive load in the experimental group (structured). Thus, the structured mode is more beneficial for the group of pre-service teachers in producing significantly less cognitive load.

A similar result was found after analysing the data collected by the semi-structured interviews. The pre-service teachers of the experimental group experienced little to no cognitive load. The pre-service teachers of the control group reported more cognitive load. This was mainly the case when a pupil tried to explain something to the pre-service teacher at the same time as (long) messages of the coach were whispered. At that moment, the information of two sources was competing for the attention of the pre-service teacher. Two pre-service teachers were disturbed by the long messages and had difficulties continuing their lessons:

Sometimes I had to listen, really listen, and listen and listen again. While I was making notes on the chalkboard, I stood there and simply wait. I heard something, so I 
waited ... and waited ... and waited until Anja [coach] stopped with whispering her long message. I had the strongest feeling that the pupils were looking at me with 'You are waiting for what?' This was a very strange feeling.

The experienced cognitive load was described in several ways. Two pre-service teachers mentioned that some messages produced 'inner doubt':

I have a good relationship with my coach and I take his criticism and tips very serious. But sometimes it was impossible to give attention to certain messages. Then, I found it annoying that I had to ignore her messages.

Cognitive load could also be caused because the message was 'stored' in the brain:

I didn't react immediately to a message. I incorporated that message in my head and then tried it out at a certain moment something happened ... and not immediately. That was more natural.

Also, the use of ear bug can cause cognitive load. If the ear bug is not well placed into the ear, it demands extra attention:

I had the feeling that my coach had laid down the transmitter for my ear piece so it felt if the communication was stopped. That gave me an uncertain feeling.

On analysis of the keywords (Instrument 3) we found, once again, similar results. On average there are fewer words per message used in the experimental group (structured). This was significantly different with the control group (ad hoc whispering). An independent-samples $t$-test was conducted to compare the average of used words per message. There was a significant difference in scores for the experimental group $(M=1.91, S D=0.51)$ and the control group $(M=10.07$, $S D=8.23 ; t[n]=20, p=0.04)$. Taking the criterion of three or four keywords into account (Scheeler, Macluckie, and Albright 2008), we can conclude that the structured mode produced less cognitive load for pre-service teachers (see Table 2).

For ambiguity of messages we also used three different measurements: (1) a questionnaire, (2) an interview and (3) an analysis of the keywords. For the questionnaire we found on one characteristic of Norton's ('unclear') a significant difference. An independent-samples $t$-test showed a significant difference related to perceived unclearness for the pre-service teachers of the experimental group $(M=1.09, S D=0.30)$ and the control group $(M=1.56, S D=0.52 ; \mathrm{t}[n]=20$, $p=.0 .03$ ). The magnitude of the difference in the means was large (Cohen's $d=1.18$ ). The higher scores of the control group represent a higher level of perceived unclearness. Reversed, for the experimental group, the levels of perceived unclearness are lower. Therefore there are indications to conclude that the structured mode produces less ambiguity for pre-service teachers.

We found an equivalent result for ambiguity as a result of using Instrument 2. In this semi-structured interview it was asked if messages caused ambiguity. The preservice teachers in the experimental group experienced almost no ambiguity. The pre-service service teachers in the control group experienced more ambiguity. On the question of whether the messages were understood, three out of nine pre-service 
Table 2. Average number of words used per message.

\begin{tabular}{|c|c|c|c|c|}
\hline Group & $\begin{array}{l}\text { Pair (coach and pre- } \\
\text { service teacher) }\end{array}$ & $\begin{array}{c}\text { Number of } \\
\text { messages used }\end{array}$ & $\begin{array}{l}\text { Number of } \\
\text { words used }\end{array}$ & $\begin{array}{l}\text { Average number of } \\
\text { words per message }\end{array}$ \\
\hline Control $^{\mathrm{a}}$ & Pair 1 & 11 & 57 & 5.2 \\
\hline Control & Pair 2 & 40 & 187 & 4.6 \\
\hline Control & Pair 3 & 21 & 101 & 4.8 \\
\hline Control & Pair 4 & 20 & 501 & 25 \\
\hline Control & Pair 5 & 18 & 270 & 15 \\
\hline Control & Pair 6 & 59 & 350 & 5.9 \\
\hline Control & Pair 7 & 8 & 35 & 4.4 \\
\hline Control & Pair 8 & 22 & 474 & 21.5 \\
\hline Control & Pair 9 & 27 & 116 & 4.3 \\
\hline Experimental $^{\mathrm{b}}$ & Pair 1 & 5 & 12 & 2.4 \\
\hline Experimental & Pair 2 & 2 & 4 & 2 \\
\hline Experimental & Pair 3 & 7 & 14 & 2 \\
\hline Experimental & Pair 4 & 4 & 9 & 2.3 \\
\hline Experimental & Pair 5 & 9 & 19 & 2.1 \\
\hline Experimental & Pair 6 & 4 & 9 & 2.3 \\
\hline Experimental & Pair 7 & 3 & 4 & 0.8 \\
\hline Experimental & Pair 8 & 8 & 9 & 1.1 \\
\hline Experimental & Pair 9 & 9 & 16 & 1.8 \\
\hline Experimental & Pair 10 & 3 & 7 & 2.3 \\
\hline Experimental & Pair 11 & 5 & 10 & 2 \\
\hline
\end{tabular}

Notes: ${ }^{\mathrm{a} C}$ Control group using ad hoc feedback, ${ }^{\mathrm{b}}$ Experimental group using structured feedback.

teachers in the control group answered that they did not understand one or more messages. One pre-service teacher said:

There were several moments that I was thinking 'What is she [coach] saying?' I had totally no idea what was meant with certain messages. It had been more ideal when I received short commando such as 'You should pay attention to Alex' or 'stop writing ... the children aren't paying any attention'. That would help much better.

Moreover, much effort must be made to understand the message clearly.

On analysis of the content of the keywords (Instrument 3) we found a similar result. Almost one message out of five (42 of 226, 19\%) didn't address one of the three problems but gave information on other competence developments. Therefore, according to the protocol, these messages had not been discussed in advance between coach and pre-service teacher. This could have an effect on the on-the-spot understanding of a message of the pre-service teacher, possibly resulting in more perceived ambiguity. Moreover, almost 74\% (31 of 42) of the 42 messages not addressing one of the three problems consisted of messages related to subject content competence. However, we know from Hooreman $(2008,36)$ that subject content competence is not suitable to be synchronous coached because 'the pre-service teacher does not comprehend the whispering of the keywords of the behaviour indicator of the subject content competence'.

\section{Conclusion and discussion}

The results of this study suggest that the use of structured keywords for delivering immediate performance feedback is more beneficial than the ad hoc mode of delivering performance feedback on the three defined problems of pre-service teachers. 
This is in line with the literature about synchronous coaching. For example, Farrell and Chandler (2008) stated that it was beneficial to create a 'code system' that allowed for minimal interaction. Beneficial is defined in terms of producing less cognitive load and ambiguity for pre-service teachers.

For ambiguity, this seems logical because in the structured mode coach and preservice teacher always have to select and discuss the keywords in advance that they are going to use. This could diminish the chance of ambiguity. In the ad hoc mode, where the protocol determined that a coach only can use the keyword on the three problems, there is a considerable chance that the coach will use keyword addressing less easy-to-understand competences, such as the subject content competence.

The reasoning related to cognitive load is slightly different. Walsh and colleagues (2009) stated that pre-service teachers have limited capacity such that they can attend to a finite amount of information simultaneously. The increased amount of cognitive processing required for performing a task while receiving, interpreting and responding to immediate feedback may impose high extraneous cognitive load on pre-service teachers (Walsh et al. 2009). By structuring the messages and only using the selected keywords, it is expected that cognitive load (i.e. extraneous load) can be reduced, resulting in lower reported levels of cognitive load. In addition, significant smaller messages were used in the structured mode, resulting in lower levels of cognitive load. This is in line with previous research, where it was stated that the number of cues should be restricted, predictable cues should be given and they should only be used for targeted lessons (Goodman et al. 2008).

There are four limitations of this study. The first has to do with the number of respondents. Because of the nature of in vivo research, the number of respondents was low. It would be beneficial to replicate this study with more teachers and to collect more data in different settings in order to support this intervention as a promising technique.

The second limitation of this experiment is that there may be more factors contributing to the cognitive load of the structured mode that were not taken into account here. Although our results are in line with Cognitive Load Theory (Sweller 1990), we concentrated only on the 'extraneous load' as a part of cognitive load. By structuring and reducing the keywords, we have lessened the chance that preservice teachers are in a state of split attention. This alleviates the extraneous load. But there are also two other parts of the cognitive load: the 'intrinsic load' (e.g. simultaneous activities in a class room) and the 'germane load' (e.g. working memory of the pre-service teacher). Recommendations for future research on decreasing cognitive load could include variations in class size, with fewer pupils and more experienced (e.g. four years) pre-service teachers.

The third limitation pertaining to this experiment is that only three problems of pre-service teachers were addressed. It would be interesting in future research to determine what other keywords can be the effectiveness and the social validity of each of these techniques in teacher preparation.

The final limitation is that there wasn't an existing scale to measure ambiguity. We composed a scale on the basis of the literature. Although the two other instruments give the same indication towards ambiguity, other scales of ambiguity should be used in future research concerning structured immediate performance feedback.

Further research in the area of BIE technology should include four domains. The first domain is that of investigating the maintenance of performance of preservice teachers who were coached using BIE technology. Most of the studies of 
immediate performance feedback address the acquisition of specific behaviour. It is also desirable to investigate whether this behaviour still exists after a certain period. The second domain includes research on the effects of delivering immediate performance feedback. Research on the effectiveness of a coaching programme can be done on four levels, according Kirkpatrick and Kirkpatrick (2006): (1) level of reaction, (2) level of learning knowledge, skills and attitudes, (3) level of behaviour (change in behaviour of pre-service teacher) and (4) level of results (effects on pupils). The third domain contains research on the characteristics of a coach who is excellent in delivering immediate performance feedback. Also, different educational settings can give a different picture for giving structured immediate performance feedback. The fourth domain of further research is about pairing with other technology such as, for example, videotaping.

If professionals in the field of teacher education wish to improve the effectiveness of synchronous coaching, they should seek ways to implement the identified attributes in efficient and consistent ways (Scheeler, Bruno, and Grubb 2009). The challenges faced by teacher-preparation programmes are enormous. Structured immediate performance feedback could help pre-service teachers know what to teach and how to teach it when they enter the school setting.

\section{Acknowledgements}

We would like to thank Guido Lejeune for his help with the data collection.

\section{Notes on contributors}

Nele Coninx works at the Fontys Teacher Education Institute in Sittard and at the Eindhoven School of Education in Eindhoven, both in the Netherlands. Her PhD focused on measuring the effects of synchronous coaching. She also works closely with coaches as a teacher educator.

Karel Kreijns is an associate professor at LOOK of the Open University in Heerlen, the Netherlands. His expertise covers multimedia didactics, computer support collaborative learning and the social psychological aspects of online learning networks.

Wim Jochems is a professor in educational innovation at the Eindhoven School of Education, University of Technology in Eindhoven. He is also director of the Teacher University in Heerlen, the Netherlands. His interests are innovations of education and in particular the role of teachers therein. Previously he was also responsible for teacher education of the University of Technology in Delft, the Netherlands and director of CELSTEC of the Open University in Heerlen.

\section{References}

Ashford, S.J. 1986. Feedback-seeking in individual adaptation: A resource perspective. Academy of Management Journal 29, no. 3: 465-87.

Black, P., and D. William. 1998. Assessment and classroom learning. Assessment in Education 5, no. 1: 7-75.

Bijou, S.W., R.F. Peterson, and M.H. Ault. 1968. A method to integrate descriptive and experimental field studies at the level of data and empirical concepts. Journal of Applied Behavior Analysis 1, no. 2: 175-91.

Bowles, E.P., and R.O. Nelson. 1976. Training teachers as mediators: efficacy of a workshop versus the bug-in-ear technique. Journal of School Psychology 14, no. 1: 15-25.

Brown, S.W. 2005. Emily and Rebecca: A tale of two teachers. Teaching and Teacher Education 21, no. 6: 637-48. 
Chandler, P., and J. Sweller. 1992. The split-attention effect as a factor in the design of instruction. British Journal of Educational Psychology 62: 233-46.

Chow, B.K., D. Mak, S.Y. Chung, and L. Louie. 2010. Transmitter assisted learning: New application in teaching and coaching sports skills. In Studies on teaching and learning, 93-8. Hong Kong: Hong Kong Baptist University.

Clutterbuck, D. 2004. Everyone needs a mentor: Fostering talent at work. London: CIPD.

Codding, R.S., A.B. Feinberg, E.K. Dunn, and G.M. Pace. 2005. The effects of immediate performance feedback on implementation of behavior support plans. Journal of Applied Behavior Analysis 38: 205-19.

Commissie Leraren. 2007. Leerkracht! [Teacher!]. Den Haag: DeltaHage.

Coulter, G.A., and B. Grossen. 1997. The effectiveness of in-class instructive feedback versus after-class instructive feedback for teachers learning direct instruction teaching behaviors. Effective School Practices 16: 21-35.

Daft, R.L., and R.H. Lengel. 1986. Organizational information requirements: Media richness and structural design. Management Science 1, no. 5: 554-71.

DeRoma, V.M., M.M. Kanetra, and M.L. Kesler. 2003. The relationship between tolerance for ambiguity and need for course structure. Journal of Instructional Psychology 30, no. 2: 104-9.

Farrell, A.C., and D. Chandler. 2008. Cooperating teachers impression of the Wisper-In-MyEar (WIME) and traditional communication feedback methods for Physical Education pre-service teachers. Journal of Education and Human Development 2, no. 1: 1-9.

Fisher, S.L., and J.K. Ford. 1998. Differential effects of learner effort and goal orientation and two learning outcomes. Personnel Psychology 51, no. 2: 397-420.

Franklin, T., C. Sexton, Y. Lu, and H.A. Ma. 2007. PDAs in teacher education: A case study examining mobile technology integration. Journal of Technology in Teacher Education 15, no. 1: 39-57.

Giebelhaus, C.R., and J. Cruz. 1994. The mechanical third ear device. An alternative to traditional student teaching supervision strategies. Journal of Teacher Education 45: 365-73.

Giebelhaus, C.R., and C.L. Bowman. 2002. Teaching mentors: Is it worth the effort? Journal of Educational Research 95, no. 4: 246-54.

Goodman, J.I. 2005. Increasing learn units by special education teachers: Supervision via bug-in-ear technology. Doctoral diss., Florida Atlantic University. Dissertation Abstracts International-A 66/01, 144.

Goodman, J.I., and M.L. Duffy. 2007. Using BUGS to increase student participation. Teaching Exceptional Children Plus 3, no. 4.

Goodman, J.I., M.P. Brady, M.L. Duffy, J. Scott, and N.E. Pollard. 2008. The effects of 'bug-in-ear' supervision on special education teachers' delivery of learn units. Focus on Autism and Other Developmental Disabilities 23, no. 4: 207-16.

Hattie, J., and H. Timperley. 2007. The power of feedback. Review of Educational Research 77, no. 1: 81-112.

Herold, P., M. Ramirez, and J. Newkirk. 1971. A portable radio communication system for teacher education. Educational Technology 11: 30-2.

Hooreman, R.W. 2008. Synchronous coaching of trainee teachers, an experimental approach; ICO Dissertation Series No. 188. Doctoral thesis, Eindhoven University of Technology.

Houtveen, T., B. Versloot, and I. Groenen. 2006. De begeleiding van beginnende leraren [Coaching of beginning teachers]. Utrecht: Sectiebestuur Onderwijsarbeidsmarkt. http:// www.onderwijsarbeidsmarkt.nl/fileadmin/user_upload/begeleiding_startende_leraren.pdf.

Hunt, D.D. 1980. Bug-in-the-ear technique for teaching interview skills. Journal of Medical Education 55: 964-6.

Kirkpatrick, D., and P. Kirkpatrick. 2006. Evaluating training programmes. 3rd ed. San Francisco, CA: Berrett-Koehler.

Kluger, A.N., and A. DeNisi. 1996. The effects of feedback interventions on performance. A historical review, a meta-analysis and a preliminary feedback intervention theory. Psychological Bulletin 119, no. 2: 254-84.

Knight, P. 2002. Summative assessment in higher education: Practices in disarray. Studies in Higher Education 27, no. 3: 275-86.

Korner, I., and W. Brown. 1952. The mechanical third ear. Journal of Consulting Psychology 16, no. 1: 81-4. 
Kulhavy, R.W., and W.A. Stock. 1989. Feedback in written instruction: The place of response certitude. Educational Psychology Review 1, no. 4: 279-308.

Locke, E.A., and G.P. Latham. 1984. Goal setting: A motivational technique that works. Englewood Cliffs, NJ: Prentice Hall.

Marzano, R.J., D.J. Pickering, and J.E. Pollock. 2001. Classroom instruction that works: Research-based strategies for increasing student achievement. Alexandria, VA: Association for Supervision and Curriculum Development.

Marzano, R.J., D.J. Pickering, and J.E. Pollock. 2009. Wat werkt in de klas [What works in the classroom]. Vlissingen: Bazalt.

Mory, E.H. 1992. The use of informational feedback in instruction: Implications for future research. Educational Technology Research and Development 40, no. 3: 5-20.

Noell, G.H., J.C. Witt, L.H. LaFleur, B.P. Mortenson, D.D. Ranier, and J. LeVelle. 2000. Increasing intervention implementation in general education following consultation: A comparison of two follow-up strategies. Journal of Applied Behavior Analysis 33: 271-84.

Noell, G.H., G.J. Duhon, S.L. Gatti, and J.E. Connell. 2002. Consultation, follow-up, and behavior management intervention implementation in general education. School Psychology Review 3: 217-34.

Norton, R.W. 1975. Measurement of ambiguity tolerance. Journal of Personality Assessment 39, no. 6: 607-19.

O'Reilly, M.F., A. Renzaglia, M. Hutchins, L. Koterba-Bass, M. Clayton, J.W. Halle, et al. 1992. Teaching systematic instruction competencies to special education student teachers: An applied behavioral supervision model. Journal of the Association for Persons with Severe Handicaps 17: 104-11.

O'Reilly, M.F., A. Renzaglia, and S. Lee. 1994. An analysis of acquisition, generalization and maintenance of systematic instruction competencies by pre-service teachers using behavioral supervision techniques. Education and Training in Mental Retardation and Developmental Disabilities 29: 22-33.

Owen, W., and R. Sweeney. 2002. Ambiguity tolerance, performance, learning, and satisfaction: A research direction. Paper presented at the Information Systems Education Conference, San Antonio.

Paas, F., J.J.G. Van Merriënboer, and J.J. Adam. 1994. Measurement of cognitive-load in instructional research. Perceptual and Motor Skills 79: 419-30.

Paas, F., J. Tuovinen, H. Tabbers, and P.W.M. Van Gerven. 2003. Cognitive load measurement as a means to advance cognitive load theory. Educational Psychologist 38: 63-71.

Peard, R., and P. Hudson. 2006. Mentoring pre-service primary teachers in mathematics. Proceedings of EDU-COM 2006 Conference, Engagement and empowerment: New opportunities for tertiary education in the twenty-first century, 226-31. Thailand: Koen Khan University.

Rathel, J.M., E. Drasgow, and C.C. Christle. 2008. Effects of supervisor performance feedback on increasing pre-service teachers positive communication behavior with students with emotional and behavioral disorders. Journal of Emotional and Behavioral Disorders 16, no. 2: 67-77.

Rock, M.L., M. Gregg, B.K. Thead, S.E. Acker, R.A. Gable, and N.P. Zigmond. 2009. Can you hear me now? Evaluation of an online wireless technology to provide real-time feedback to special education teachers-in-training. Teacher Education and Special Education 32, no. 1: 64-82.

Rose, D.J., and R.J. Church. 1998. Learning to teach: The acquisition and maintenance of teaching skills. Journal of Behavioral Education 8: 5-35.

Ross, P.M., and D.A. Tronson. 2005. Providing quality feedback. Where to from here? In Proceedings of scholarly inquiry into science teaching and learning symposium. Sydney: UniServe Science.

Rushton, S.P. 2003. Two pre-service teachers' growth in self-efficacy while teaching in an inner-city school. Urban Review 35, no. 3: 167-89.

Sadler, D.R. 1989. Formative assessment and the design of instructional systems. Instructional Science 18: 119-44.

Sadler, R. 1998. Formative assessment: Revisiting the territory. Assessment in Education 5, no. 1: 77-85. 
Scheeler, M.C., K. Bruno, and E. Grubb. 2009. Generalizing teaching techniques from university to K-12 classrooms: Teaching pre-service to use what they learn. Journal of Behavioral Education 18: 189-210.

Scheeler, M.C., and D.L. Lee. 2002. Using technology to deliver immediate corrective feedback to pre-service teachers. Journal of Behavioral Education 11, no. 4: 231-41.

Scheeler, M.C., J.K. McAfee, K.L. Ruhl, and D.L. Lee. 2006. Effects of corrective feedback delivered via wireless technology on pre-service teacher performance and student behaviour. Teacher Education and Special Education 29, no. 1: 12-25.

Scheeler, M.C., K.L. Ruhl, and J.K. McAfee. 2004. Providing performance feedback to teachers: A review. Teacher Education and Special Education 27, no. 3: 396-407.

Scheeler, M.C., M. Macluckie, and K. Albright. 2008. Effects of immediate feedback delivered by peer tutors on the oral presentation skills of adolescents with learning disabilities. Remedial and Special Education 11: 1-10.

Shute, V. 2008. Focus on formative feedback. Review of Educational Research 78, no. 1: 153-89.

Simpson, J.A., and E.S. Weiner. 1999. The Oxford English dictionary. Oxford: Oxford University Press.

Stroot, S., V. Keil, P. Stedman, L. Lohr, R. Faust, L. Schincariol-Randall, A. Sullivan, G. Czerniak, J. Kuchcinski, N. Orel, and M. Richter. 1998. Peer assistance and review guidebook. Columbus, OH: Ohio Department of Education.

Sutherland, K.S., N. Alder, and P.L. Gunter. 2003. The effects of varying rates of opportunities to respond to academic requests on the classroom behavior of students with EBD. Journal of Emotional and Behavioral Disorders 11: 239-48.

Sweller, J. 1990. Cognitive processes and instruction procedures. Australian Journal of Education 34, no. 2: 125-30.

Sweller, J., J.J.G. Van Merriënboer, and F. Paas. 1998. Cognitive architecture and instructional design. Educational Psychology Review 10, no. 3: 251-96.

Thomson, C.L. 1978. An experimental analysis of some procedures to teach priming and reinforcement skills to preschool teachers. Monographs of the Society for Research in Child Development 43, no. 4: 1-86.

Van Houten, R. 1980. Learning through feedback. New York: Human Sciences Press.

Veenman, S. 1984. Perceived problems of beginning teachers. Review of Educational Research 54, no. 2: 143-78.

Walsh, C.M., S.C. Ling, C.S. Wang, and H. Carnahan. 2009. Concurrent feedback versus terminal feedback: It may be better to wait. Academic Medicine 84, no. 10: 54-7.

Westers, F., and V. Peters. 2004. Kwalitatieve analyse: Uitganspunten en procedures [Qualitative analyses: Main points and procedures]. Bussum: Uitgeverij Coutinho.

Wong, H.K., T. Britton, and T. Gasner. 2004. What the world can teach us about improving new teacher induction. Phi Delta Kappan 86, no. 5: 379-84. 